\title{
Integrating a New Dietetic Care Process in a Health Information System: A System and Process Analysis and Assessment
}

\author{
Gabriele Gäbler ${ }^{1, *} \mathbb{C}$, Deborah Lycett $^{2} \mathbb{(}$ and Walter Gall ${ }^{3}$ \\ 1 Department of Science, Research and Development, Austrian Association of Dietitians, Grüngasse 9, \\ 1050 Vienna, Austria \\ 2 Centre for Intelligent Healthcare, Coventry University, Priory Street, Coventry CV1 5FB, UK; \\ ab5042@coventry.ac.uk \\ 3 Center for Medical Statistics, Informatics and Intelligent Systems, Medical University of Vienna, \\ Spitalgasse 23, 1090 Vienna, Austria; walter.gall@meduniwien.ac.at \\ * Correspondence: gabriele.gaebler@diaetologen.at
}

check for

updates

Citation: Gäbler, G.; Lycett, D.;

Gall, W. Integrating a New Dietetic

Care Process in a Health Information

System: A System and Process

Analysis and Assessment. Int. J.

Environ. Res. Public Health 2022, 19,

2491. https://doi.org/10.3390/

ijerph19052491

Academic Editors: George Crooks

and Pentti Nieminen

Received: 15 December 2021

Accepted: 16 February 2022

Published: 22 February 2022

Publisher's Note: MDPI stays neutral with regard to jurisdictional claims in published maps and institutional affiliations.

Copyright: (C) 2022 by the authors. Licensee MDPI, Basel, Switzerland. This article is an open access article distributed under the terms and conditions of the Creative Commons Attribution (CC BY) license (https:// creativecommons.org/licenses/by/ $4.0 /)$.

\begin{abstract}
Managing routinely collected data in health care and public health is important for evaluation of interventions and answering research questions using "real life" and "big data". In addition to the technical requirements of information systems, both standardized terminology and standardized processes are needed. The aim of this project was to analyse and assess the integration of standardized terminology and document templates for a dietetic care process (DCP) into the health information system (HIS) in a hospital in Austria. Using an action research approach, the DCP was analysed through four expert interviews and the integration into the HIS through two expert interviews with observations. Key strengths and weaknesses for the main criteria ("integration of the ICF catalogue", "adaption of the document templates", "adaption of the DCP", and the "adaption of the user authorizations") were presented and proposals for improvement given. The system and process integration of the DCP is possible, and the document templates can be adapted with the software currently in use. Although an increase in resources and finances required is to be expected initially, the integration of a standardized dietetic terminology in combination with a standardized process is likely to improve the quality of care and support outcomes management and research.
\end{abstract}

Keywords: standardized terminology; International Classification of Functioning, Disability, and Health (ICF)-Dietetics; nutrition and dietetics; clinical documentation; health information system; electronic health record

\section{Introduction}

Managing routine outcome data is essential for auditing and benchmarking, evaluating current interventions and conducting pragmatic research on big data in health care and public health [1,2]. The use of a standardized care process and standardized terminology for the documentation of individual therapy and population-level interventions provides clear, unambiguous terms to support the comparability and management of routinely collected data $[3,4]$.

This is supported by the World Health Organization (WHO) in their recommendation to use the International Classification of Functioning, Disability, and Health (ICF), a multipurpose classification for various disciplines describing the functional state of health and its contextual factors $[5,6]$. Use of the ICF is recommended in combination with the International Classification of Diseases (ICD) [7] and the International Classification of Health Interventions (ICHI) [8,9]. Together, these capture the situation of patients at a given point in time and cover the most important parts of the health system $[5,10]$. They are a reference system supporting clinical practice and data collection at the individual (micro), institutional (meso) and social (macro) level $[8,11]$ of the health system. The ICF 
is considered a third health indicator (in addition to mortality and morbidity) that can be used to monitor the achievement of health strategies at all these levels [12].

Numerous articles can be found regarding ICF. These describe how the ICF framework can be used in multidisciplinary health care [13-18] and discuss the development and validation of ICF Core Sets (sets of ICF categories relevant for patients with a certain heath condition) to facilitate multidisciplinary assessment [19-27]. Articles compare the content of instruments to measure functioning of patients [28-35] and describe the linking of problems experienced from a patient perspective in daily life [36-38]. Furthermore, studies discuss the implementation of ICF-based tools in clinical practice [39-46] and ICF use in electronic health records (EHRs) $[47,48]$.

Although the ICF is used by various health professions, e.g., physicians, nurses, physiotherapists, occupational therapists, and speech therapists, it has not yet been used by dietitians (dietitians are a legally recognized health profession and in Austria belong to the Higher Medical-Technical Professions (MTDs) [49]). The ICF was lacking in dieteticsrelated categories and unsuitable for the documentation of the dietetic care process (DCP) until the Dutch Association of Dietitians, in collaboration with the Dutch Institute of Allied Health Care, expanded the ICF with approximately 900 dietetics-related categories [50]. This ICF-Dietetics is part of the Classifications and Coding Lists for Dietetics (CCD) in the Netherlands [51]. The CCD was developed as a standardized dietetics terminology and consists of various classifications and coding lists, e.g., a classification for interventions modified by the ICHI and a list of goals [51]. The second standardized dietetics terminology applied worldwide is the Nutrition Care Process Terminology (NCPT) developed by the American Academy of Nutrition and Dietetics, which is exclusively a nutrition and dietetics terminology [51]. Beginning with an action research process, the ICF-Dietetics was compared with the NCPT, translated, validated, and clinically pre-tested to develop an Austrian-German ICF-Dietetics version [52]. Document templates were developed alongside this for the DCP, based on ICF documentation tools [13,53]. A multicentre study [50] and a focus group study [54] showed that the integration of the ICF-Dietetics into the DCP was possible, and an Austria-wide implementation of the ICF-Dietetics was advocated. However, a multifaceted implementation strategy is required, with the integration of ICF-Dietetics into existing health information systems (HIS) seen as a prerequisite for a successful implementation [54].

HIS that support both structured and free text information can facilitate the collection, presentation, sharing, and use of health information [47]. In this context, standardized terminologies contribute to improving the quality and comparability of data [4,47]. The ICD of the WHO classifications is already automatically integrated into the standard software of Austrian HIS. Furthermore, the integration of the ICF into a HIS has already been explored in several studies $[4,47,55]$ as mentioned above, but standard implementation for clinical practice is not yet available [47].

The implementation of standardized terminology in a HIS requires a system analysis and system assessment as a first step [55-57]. This allows obstacles and potential for improvements to be identified, timely adaptations, and, if necessary, an alternative proposal to be made [56,58]. In hospitals, HIS are used by different providers, have different requirements, and must meet different challenges. This heterogeneity makes it necessary for this system analysis and assessment to be carried out in the context of implementation projects based on a specific HIS. Principles from learning here can be applied to other settings.

The aim of this project was therefore to analyse and assess the integration of a new DCP using standardized terminology and templates for documentation in a HIS with an existing service request called "dietological council" in a large hospital in Austria.

\section{Materials and Methods}

This study reports on a system and process technology analysis and assessment focussing on integrating a DCP into an existing HIS. This was conducted in two phases: first, analysis and assessment of the new DCP, and second, analysis of current process of 
dietetic referral ("dietological council") and assessing the integration of the new DCP. Using an action research approach [59-61] with qualitative semi-structured interviews facilitates identifying strengths and weaknesses of the system and process integration.

The DCP was developed by an expert task force based on national and international literature and using an interactive development process. It is described in detail elsewhere [62]. The clinical practicability and applicability of the ICF-Dietetics and the templates of the current study have already been evaluated earlier in nutrition and dietetic practice by means of a pre-test and focus group study in a hospital in Austria. The General Hospital of Vienna was chosen for the system and process technology analysis and assessment, as the dietitians agreed that the ICF-Dietetics would be useful and acceptable for clinical practice. They also stressed the need to integrate the new process with the document templates and standardized terminology in the HIS.

\subsection{Analysis and Assessment of the New DCP}

Four interviews were conducted by a computer scientist (principal investigator) with an academic dietitian recruited from the developers of the DCP. The interviews were structured around the five sub-processes of the DCP (dietetics assessment, dietetics diagnosis, dietetics goal setting, dietetics intervention, and dietetics evaluation). These interviews were part of an iterative development process whereby the four typical development phases of planning, doing, checking, and acting (PDCA-cycle) were performed several times in order to improve the quality of the analysis results continuously $[59,60]$. Feedback from other developers of the DCP and the interviewer also played a part. During this process, graphical representations of the new DCP and a precise description for the analysis and assessment with respect to its five sub-processes were carried out by the principal investigator. The purpose of these was to develop, test, and refine the process through discussion of how it should work, of what works well and what barriers arise. The graphical representation of the new DCP with reference to the document templates and the standardized terminology (classification catalogues) was depicted in a simplified process diagram (Figure 1). This is described in detail in Supplementary Material S1 (Figures S1-S4). (The referral required according to $\S 2$ of the MTD law [49] in case of a medical diagnosis is not shown explicitly in Figure 1, since the focus is on the implementation of the new DCP by dietitians, and this starts with the assessment. Expert systems and clinical decision support were hypothetically included in the interviews (Supplementary Material S1), but were not assessed).

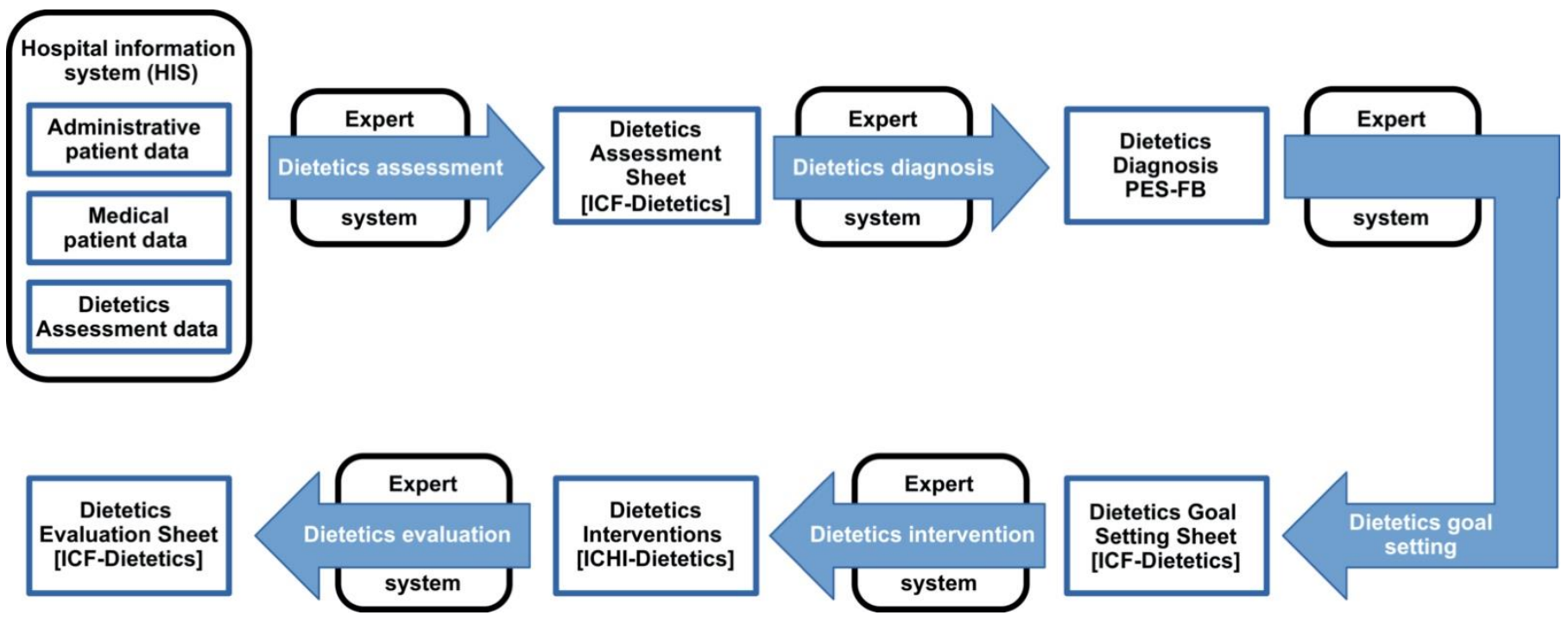

Figure 1. New DCP with document templates and standardized terminology (adapted from Krottenmüller [63]). 
The ICF-Dietetics is the only classification catalogue available for implementation at the time of the project. Further catalogues for nutrition-related problems and nutrition related goals are planned and therefore were already taken into account in the description of the new DCP. Similarly, the planned classification catalogue for interventions for dietetics was integrated and referred as ICHI-Dietetics, because it should be based on the ICHI [9] and adopted for dietetics.

\subsection{Analysis of Current System of Dietetic Referral ("Dietological Council") and Assessing the Integration of the New DCP}

Two further interviews, together with on-site observations of use of the current process, were conducted by the principal investigator with the leading dietitian of the hospital. These interviews also formed part of an interactive process with feedback from other dietitians of the hospital. During this development process, the current process was visualized as a business process model ("extended event-driven process chain" (eEPC) [64,65]) and used as a framework for assessing the integration of the new DCP within it. The current process is divided into four sub-processes due to its complexity (Figure 2). The whole business process model is shown and described in Supplementary Material S2 (Table S1 and Figures S4-S8). The following specific requirements were applied to the modelling language of the current process: 1 . Trivial notation elements for users without modelling expertise, kept as general as possible and representable without additional specifics or explanations; 2. Modelling language close to the existing enterprise resource planning (ERP) software SAP, and standardized modelling language that enables processing by external persons. The software "EdrawMax" [66] was used for modelling.

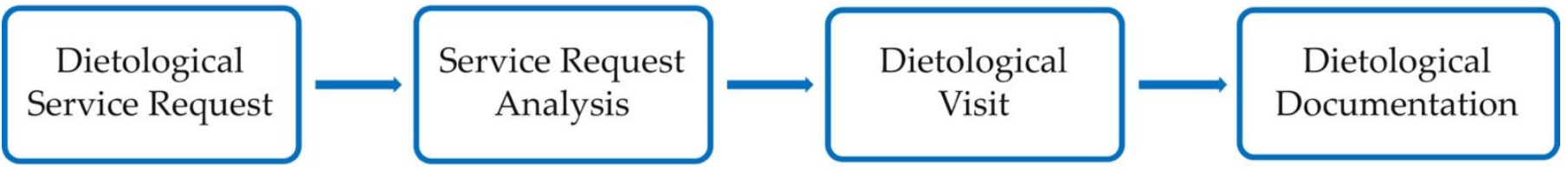

Figure 2. Sub-processes of the current system "dietological council" (adapted from Krottenmüller [63]).

Qualitative data of the assessment was mapped against four main criteria that are important for the integration of a new process with documents and standardized terminologies: for the system integration, the "integration of the ICF catalogue" and the "adaption of the document templates", and for the process integration, the "adaption of the new DCP" and the "adaption of the user authorizations".

\section{Results}

The key strengths and weakness of the system and process technology integration ("integration of the ICF catalogue", "adaption of the document templates", "adaption of the new DCP", and the "adaption of the user authorizations") are summarised in Table 1 and explained below with examples of proposals for improvement. Further detailed descriptions and suggestions for improvement can be found in Supplementary Materials S1 and S2.

\subsection{System Integration Aspects (Integrating the New DCP into the Current Process 'Dietological Council')}

The service request "dietological council" of the current process uses the HIS with an EHR to create the documents. The implemented HIS software is SAP [67] with the modules "IS-H" [68] and "i.s.h.med" [69]. Dietitians are fully integrated in both modules. No additional software is required. The system activities for dietitians include access to patient data, changes of "service requests", performance indicator entry, and documentation. The written documents use parameterized documents (documents that have already specified certain parameters, values, or variables) with free text and text templates. 
Table 1. Summary of results mapped against the four criteria for the system and process integration: "integration of the classification catalogues", "adaption of the document templates", "adaption of the new DCP", and "user authorizations".

\begin{tabular}{|c|c|c|c|}
\hline Current Process & New DCP ${ }^{5}$ & Strength/Facilitators & Weakness/Obstacles \\
\hline \multicolumn{4}{|c|}{ System } \\
\hline used software is SAP ${ }^{1}$ & $\begin{array}{l}\text { software remains SAP } \\
\text { no additional software is required }\end{array}$ & $\begin{array}{l}\text { dietitians are fully integrated in } \\
\text { the current system }\end{array}$ & \\
\hline \multicolumn{4}{|c|}{ Integration of the classification catalogues } \\
\hline no catalogues & $\begin{array}{l}\text { ICF }^{6} \text {-Dietetics (available) } \\
\text { ICHI }{ }^{7} \text {-Dietetics (in process of } \\
\text { planning) } \\
\text { nutrition-related problems } \\
\text { (available as word file) } \\
\text { dietetics diagnosis (in process of } \\
\text { planning) } \\
\text { dietetics goals (in process of } \\
\text { planning) }\end{array}$ & $\begin{array}{l}\text { classification catalogues, such as } \\
\text { the ICD- } 10^{8} \text { catalogues, are } \\
\text { already implemented in the } \\
\text { existing system, and its importing } \\
\text { programs can be used as template } \\
\text { and be adapted } \\
\text { Excel format of the ICF-Dietetics } \\
\text { facilitate the implementation }\end{array}$ & $\begin{array}{l}\text { an ontological search within } \\
\text { ICF-Dietetics catalogues is not } \\
\text { possible } \\
\text { not all catalogues are available }\end{array}$ \\
\hline \multicolumn{4}{|c|}{ Adaption of the document templates } \\
\hline $\begin{array}{l}\text { all information in one document } \\
\text { "dietological council" using } \\
\text { parameterized documents }\end{array}$ & $\begin{array}{l}\text { four documents: } \\
\text { "ICF-Dietetics Assessment Sheet" } \\
\text { "ICF-Dietetics Goal Setting Sheet" } \\
\text { "ICHI-Dietetics Intervention } \\
\text { Sheet" } \\
\text { "ICF-Dietetics Evaluation Sheet" }\end{array}$ & $\begin{array}{l}\text { an adaption of the currently used } \\
\text { document is possible } \\
\text { parameterized documents can } \\
\text { take over data from other } \\
\text { documents, thus enabling coding }\end{array}$ & $\begin{array}{l}\text { ICF-Dietetics and its } \\
\text { bio-psycho-social model restrict } \\
\text { the documentation templates of } \\
\text { the assessment }\end{array}$ \\
\hline \multicolumn{4}{|c|}{ Process in general } \\
\hline $\begin{array}{l}\text { applied according to the } \mathrm{MTD}^{2} \\
\text { law and internal work } \\
\text { instructions }\end{array}$ & $\begin{array}{l}\text { corresponds to the MTD law and } \\
\text { internal work instructions of the } \\
\text { MTDs }\end{array}$ & $\begin{array}{l}\text { enables transparent } \\
\text { documentation }\end{array}$ & $\begin{array}{l}\text { increase in resources and finances } \\
\text { required, e.g., portable devices }\end{array}$ \\
\hline $\begin{array}{l}\text { the service request "dietological } \\
\text { council" uses the HIS }{ }^{3} \text { with an }\end{array}$ & five sub-processes & $\begin{array}{l}\text { enables efficient and effective } \\
\text { workflow in intra- and } \\
\text { interprofessional areas }\end{array}$ & $\begin{array}{l}\text { complexity of coding } \\
\text { support tools are needed }\end{array}$ \\
\hline $\begin{array}{l}\text { EHR }^{4} \text { to create the documents } \\
\text { four sub-processes }\end{array}$ & $\begin{array}{l}\text { documentation with new } \\
\text { templates and standardized } \\
\text { terminologies }\end{array}$ & $\begin{array}{l}\text { enable the evaluation and } \\
\text { comparison of outcomes }\end{array}$ & $\begin{array}{l}\text { document templates generally } \\
\text { missing patient data (header) }\end{array}$ \\
\hline \multicolumn{4}{|c|}{ Adaption of the new DCP } \\
\hline "Dietological service request" & no corresponding part & & \\
\hline "Service request analysis" & first part of dietetics assessment & $\begin{array}{l}\text { automatic transfer of data from } \\
\text { EHR is possible }\end{array}$ & $\begin{array}{l}\text { no fields are provided for } \\
\text { automatic transfer } \\
\text { currently only free text }\end{array}$ \\
\hline "Dietological visit" & $\begin{array}{l}\text { dietetics assessment } \\
\text { "ICF-Dietetics Assessment Sheet" } \\
\text { dietetics diagnosis } \\
\text { "ICF-Dietetics Goal Setting Sheet" } \\
\text { dietetics goal setting } \\
\text { "ICF-Dietetics Goal Setting Sheet" } \\
\text { dietetics intervention } \\
\text { "ICHI-Dietetics Intervention } \\
\text { Sheet" } \\
\text { part of dietetics evaluation }\end{array}$ & $\begin{array}{l}\text { structured implementation of data } \\
\text { collection }\end{array}$ & $\begin{array}{l}\text { type of diagnosis is missing } \\
\text { manner of PES-FB }{ }^{9} \text { statement } \\
\text { manner of goal setting } \\
\text { dietetics aid catalogues and } \\
\text { patient letter/final report are } \\
\text { missing }\end{array}$ \\
\hline "Dietological Documentation" & part of dietetics evaluation & & $\begin{array}{l}\text { information and findings are } \\
\text { documented in several documents }\end{array}$ \\
\hline \multicolumn{4}{|c|}{ User authorizations } \\
\hline $\begin{array}{l}\text { carry out the process without } \\
\text { restrictions }\end{array}$ & $\begin{array}{l}\text { additional administrative data are } \\
\text { required }\end{array}$ & $\begin{array}{l}\text { authorizations allow dietitians to } \\
\text { carry out their process without } \\
\text { restrictions }\end{array}$ & $\begin{array}{l}\text { a system-based authorization } \\
\text { adaptation and data protection } \\
\text { are required }\end{array}$ \\
\hline
\end{tabular}

${ }^{1}$ Systems Applications Programs. ${ }^{2}$ Higher Medical-Technical Professions. ${ }^{3}$ Health Information System. ${ }^{4}$ Electronic Health Record. ${ }^{5}$ Dietetic Care Process. ${ }^{6}$ International Classification of Functioning, Disability and Health. ${ }^{7}$ International Classification of Health Interventions. ${ }^{8}$ International Classification of Diseases Version $10 .{ }^{9} \mathrm{Di}-$ etetics diagnosis formulation, including the nutrition-related problems $(\mathrm{P})$, the etiology $(\mathrm{E})$ and the symptoms or signs (S) of the problem and according to the ICF coding guidelines the facilitators (F) and barriers (B). 
A change or creation of the documents according to the criteria of the DCP is possible regardless of the implementation of the classification catalogues and only requires systemtechnical settings (customizing) in the "i.s.h.med". The technical integration includes the software adaptations for the implementation of the ICF-Dietetics and other classification catalogues as well as document templates for documenting the DCP.

\subsubsection{Integration of Classification Catalogues for the New DCP}

At present, neither a standardized dietetics terminology nor a general classification catalogue containing nutrition-related concepts is used. However, classification catalogues, such as the ICD-10 catalogue, are already implemented in the existing SAP "IS-H" and "i.s.h.med" systems. The only available classification catalogue for implementation of the new DCP was the ICF-Dietetics. However, the specifications for the use of the entire classification catalogues allow individual gradual adoptions, so ICF-Dietetics integration is seen as just the first step. The ICF-Dietetics is integrated into the HIS by importing the contents of the Excel worksheet into a created SAP table. This is based on the existing ICD-10 template and builds in its organizational and process-related requirements such as the validity date (start and end date). The ICF-Dietetics input file contains five columns, of which only the first (codes) and the second column (title of the category) will appear on the electronic schedule. The remaining three columns (description, inclusion, and exclusion) are only visible when the search or coding input help is activated. Using this input help, the search for texts can be carried out in all five input fields. An ontological search is not possible. The technical adaptation options of the existing Excel format and the trivial technical structure facilitate the implementation of the ICF-Dietetics. Thus, the current system meets the requirements for the technical implementation of ICF-Dietetics in Excel format and other catalogues with the same structure. To increase the user-friendliness and ease of work, there is the need for various support tools for users (e.g., search aids, core sets, keyword catalogue).

\subsubsection{Adaptation of the Document Templates for the New DCP}

Four documents are planned for the new DCP (Supplementary Material S1). The documents for the current process are based on the more precise SAP technology of the parameterized documents of the "i.s.h.med". The parameterized document can access all data in the SAP system so that the patient data can be fully integrated. In addition, parameterized documents can also take over data from other parameterized documents. The ICF-Dietetics catalogue entries (codes and titles) migrated into the SAP system as table contents can thus be activated for documentation in a document. The creation of the parameterized documents does not require any additional software, programming, or licenses. The documents can be created using the future terminology based on the new DCP. The layout specifications (such as font, font size, and patient header) can be adopted from the existing diagnostic document. The structural changes (content according to the bio-psycho-social model of ICF-Dietetics) are to be implemented in the "body" (textual information) of the document. Since the description of the functional state of health is based on ICF-Dietetics and its bio-psycho-social model, it restricts the documentation templates to this model. A combined use of the ICF catalogue with the NCPT catalogue for nutrition diagnosis (nutrition problems) and interventions would, however, be possible without changing the document templates.

\subsection{Process Integration Aspects (Integrating the New DCP into the Current Process)}

The current process is subject to internal work instructions for therapeutic health professionals of the MTD group. These work instructions describe a general therapeutic process from the start (dietetics assessment of initial situation) to the end of therapy (evaluation). For the proper implementation of the new DCP, the document templates and classification catalogues must be used from the beginning of the process (the dietetics assessment). For this purpose, the dietitian must be provided with a portable device (e.g., 
laptop or tablet) that has to be used for the "dietological visit" (the patient consultation) in the future. Due to data entry, conversation with the patient can be disrupted during the visit; additionally, expenditure of work and time may be increased. In this regard, an increase in resources and financial expenditure is to be expected. In the long term, however, the new DCP is to be seen as an advantage due to an efficient and effective workflow and the possibility of outcomes research.

In general, the document templates were created without administrative patient data (header) such as name, date of birth, date of admission. However, this information is important regarding document security and clear patient identification. The structure of the header will be created according to the specifications of the respective hospital administration and the minimum necessary for the performance requirements.

\subsubsection{Adaption of the New DCP}

The new aspects of the DCP are mainly due to the integration and use of new document templates and standardized terminology and not a change in the process flow, as shown in the eEPC framework (Supplementary Material S2). The potential for improvement primarily relates to the document templates (e.g., the documentation of dietetics diagnosis and goal setting), as described in Supplementary Material S1. The implementation of the new features of the DCP requires the creation of at least two electronic documents, the "ICF-Dietetics Assessment Sheet" and the "ICF-Dietetics Goal Setting Sheet".

If several dietological services are carried out during an inpatient hospital stay, many dietological documents must be created. This can lead to difficulties and misunderstandings, especially if related dietological documents contain different creation dates. A reference on the created documents to the associated documents would simplify the problem. This can be done by referring to the creation date of the associated documents or an ID (e.g., referral ID) on the dietological document. The reduction in the number of documents per care process can improve the overview of the dietological documents in the intra- and interdisciplinary area and makes administration easier. One possibility for simplification would be the illustration (output file) of the therapy report and the subdivision of the document into the respective documents of the sub-process using separate tabs. The new DCP depicted here does not contain a written document that can be given to the patient as a final report or therapy report. It is recommended in any case to integrate a semi-automatic final report as summary of important information, e.g., dietetics diagnosis, the goals, and the interventions.

\subsubsection{Adaption of the User Authorizations}

The existing authorizations allow dietitians to carry out their process without restrictions. For integration of the new DCP with new templates and standardized terminologies, additional administrative data (e.g., living situation) are required for dietetics' diagnosis formulation, which could go beyond the current system-technical settings. A system-based authorization adaptation would have to be implemented as well as an evaluation in terms of data protection. The new DCP may require adaptations in the documentation. When data is entered by the dietitian (e.g., weight), it must be checked whether the data entered are only saved and visible in the dietological document or are generally made available in the EHR of the HIS.

The input of medical data into a HIS is carried out by the various health professionals. It must be noted whether certain patient data from other professional groups are also documented in the HIS or on paper. If medical patient data (e.g., weight) is saved in the EHR and not directly in the document of dietitians, the respective implementation authorizations (saving, changing, and deleting) for the respective areas must be checked and structured. 


\section{Discussion}

This work demonstrates a system and process analysis and assessment for the integration of a new therapeutic process, the DCP, with a standardized terminology and document templates in an existing HIS. The study used an action research approach. The implementation of the DCP and standardized terminology in HIS will support the documentation of the individual care process and thus quality assurance, e.g., transparency and continuity of care $[3,70]$, on the one hand and facilitate the comparison of data and thus outcomes management and research on the other hand. As a result, best practice methods could be established and the effectiveness of care improved [3]. Moreover, no study was found in the literature that describes the analysis and assessment of the integration of a therapeutic process with standardized terminology. Thus, our detailed description, assessment, and proposals for improvement can assist others in integrating the DCP and the ICF-Dietetics in their HIS. Our study can therefore be of interest to other institutions in Austria as well as in other countries.

However, we want to emphasize that the change of a process must also take into account the non-technical aspects. During an information system analysis and assessment, it is important that the people involved in the process with their roles and skills are considered accordingly. Therefore, established process models for system analysis and assessment use two dimensions to categorize the areas of the criteria, namely, organizational aspects and the technical aspects of information tools [55,57]. Our system and process analysis and assessment build on a previous pre-test and focus group study, which evaluated the clinical practicability and applicability of the new DCP with the ICF-Dietetics and the templates as a "paper and pencil" version [54]. For this reason, we focused our findings to four main criteria which are important for the integration of a new process with documents and standardized terminologies: "integration of the classifications catalogue"; "adaption of the document templates"; "adaption of the new DCP"; and the "adaption of the user authorizations". Our results showed strengths and weaknesses in each of these areas; these were consistent with other literature as described below, and obstacles were considered surmountable. In accordance with action research $[59,60]$, the implementation of the new process will be evaluated in an implementation project and will be described elsewhere.

\subsection{Integration of the ICF Catalogue}

A great advantage of the ICF-Dietetics is that it is based on a main classification of the WHO that can be used in multidisciplinary patient management $[47,54]$. A disadvantage is that an ontological search within ICF-Dietetics as in "DIACOS" [71] is not possible. Maritz et al. [47] and Bales et al. [72] also mention two disadvantages of the ICF: first, that it does not correspond to all features of a formal terminology (it is not yet interoperable), and second, that an ontology is not yet available. However, the "ICF Practice Manual" [73] states that an ontological presentation of the ICF has been in progress since 2008 in order to be compatible with e-health systems. Two aspects are explicitly mentioned in order to facilitate the integration of the ICF in EHRs: first, the formalization of the knowledge representation in ICF (ontology development), and second, the establishment of linking with other clinical terminologies (e.g., SNOMED CT). Both aspects will be important for the application of ICF-Dietetics in the future. Health professionals need a wide range of clinical and administrative patient data available in EHRs for their daily work. To support health professionals in sharing EHRs, integrated communication by means of vocabularies such as SNOMED CT or LOINC is crucial [4]. Therefore, in the future, mappings to other terminologies, especially to SNOMED CT, will enable the international exchange of ICF data in standardized data models [74-76] and facilitate big data analysis [77]. To this end, linkage to other established vocabularies is an important goal in addition to establishing a uniform framework and language in dietetics.

It can be assumed that standardized terminologies will become indispensable for the fulfilment of quality criteria in the health sector, such as patent orientation, transparency, effectiveness, and efficiency [78,79]. This implies that the optimization and further 
development of these terminologies will take place quickly. Experience in the application of ICF/ICF-Dietetics shows that due to the complexity and number of categories (approx. 2400), assigning the optimal category (coding) is found to be difficult and timeconsuming $[54,80]$. To increase the user-friendliness and ease of work, there is the need for various support tools for users (e.g., search aids, core sets, keyword catalogues). These support tools are essential aspects for the integration of ICF-Dietetics [81-83]. They increase acceptance and correct coding by employees.

Finally, it should be mentioned that to meet quality criteria using standardized terminology, the implementation of a new terminology is accompanied by interactive training courses on motivation, professional coding, and use $[54,79,83]$.

\subsection{Adaptation of Document Templates}

Document templates can improve the consistency and completeness of the documentation, but they can also take more time $[4,84]$. Studies have shown that precise, unrestricted free text entry is most effective for communicating and coordinating complex tasks [85]. For the dietetics goals, both the ICF-Dietetics catalogue and another special goal catalogue should be used, and free text should also be possible. However, free text in classification catalogues generally contradicts its use in electronic patient files [4]. In contrast, structured data fields are required to search and process data electronically, e.g., to evaluate the effectiveness of interventions, for research, or for administrative purposes [85].

\subsection{Adaptation of New DCP}

The new DCP is in line with the legal guidelines in accordance with the FH-MTD training regulation [86] and the MTD law [49] in Austria. It can be seen as a detailed guide for dietitians on how to provide and uniformly document care using standardized terminologies. Due to the specific procedure and the use of the classification catalogues, this new DCP contributes to the quality improvement of clinical dietetic practice, especially in terms of implementation and transparent documentation [47,70,87-89]. It increases personalized patient-oriented treatment and enables better decision making in goal setting and the selected interventions [2,3]. A multidisciplinary terminology, such as the ICF, enables efficient and effective work in intra- and interprofessional areas $[4,17,47,55]$. In addition, the standardized procedure and the use of standardized terminologies enable the evaluation and comparison of outcomes $[2,3,88]$.

\subsection{Adaption of the User Authorizations}

Due to the interdisciplinary character of a dietological service (referral by physician, service allocation by administration), adjustments can be necessary not only in dietetics, but also across departments. Entering patient data from various health professionals into the system without precise regulation can lead to redundancies and, under certain circumstances, to misunderstandings and misinterpretations. In our study, we analysed organizational aspects other than our technical aspects in terms of roles by means of the eEPC, which provided us with a clear and structured basis for the analysis and assessment and, therefore, can be recommended for other projects.

\subsection{Limitation of the Work}

A system analysis and assessment can only be carried out for one organization and application due to the heterogeneity of HIS. In this respect, these results cannot be directly transferred to other projects, but this project can be seen as an example of the methodological approach. We have focused on four criteria in this work, but a wide range of other criteria could also be important. The technical system settings of the SAP program in the area of dietitians were not taken into account for reasons of operational safety. Possible customer changes in the SAP program could therefore have remained undetected. This can lead to additional work due to implementation modifications. This aspect must be considered in a financial plan for integration. Furthermore, expert interviews may not produce 
fully objective analysis; however, in combination with feedback during the development process, we were able to increase the quality of the results. Another limitation can be seen that the catalogues were still in development; however, as described above a stepwise integration is possible. Finally, the fact that no evaluation of the implementation of the new DCP was included can be seen as a limitation of this study. In this context, we would like to emphasize our methodological approach in the sense of action research, which enables a step-by-step translation and implementation of knowledge into practice.

\section{Conclusions}

According to the project specifications, the new DCP meets the legal requirements. An integration of it with the standardized terminologies and document templates in the existing HIS is technically feasible. The representation of the current process shows that there are no system-technical obstacles, and the dietetics service request "dietological council" can be carried out with the new features of the DCP. The potential for improvement discussed does not concern the system-technical integration of the process itself but technical support tools for the user-friendliness of the classification catalogues and especially the proposed document templates. Although an increase in resources and finances required is to be expected initially, the integration of a standardized terminology in combination with a standardized process can improve the quality of care in the long term and support outcomes management and research.

Supplementary Materials: The following are available online at https:/ /www.mdpi.com/article/10 $.3390 /$ ijerph19052491/s1, Supplementary Material S1: Description of the new DCP, Supplementary Material S2: Descrip-tion of the current process and adaption of the new DCP.

Author Contributions: G.G. conceptualized and wrote the original draft, reviewed it, and revised it. W.G. was responsible for the methodical implementation, review, and revision of the manuscript. D.L. reviewed and revised the manuscript. All authors have read and agreed to the published version of the manuscript.

Funding: This research received no external funding.

Institutional Review Board Statement: This study was conducted in accordance with the Declaration of Helsinki. Ethical review and approval were waived for this study in accordance with the Ethics Committee of the Medical University of Vienna due to only expert opinions and no patient data were evaluated.

Informed Consent Statement: The dietitians who took part in the interviews were informed in detail about the study procedures and gave their verbal consent. The participation of the experts were voluntary.

Acknowledgments: We would like to thank Peter Krottenmüller, who conducted the interviews, created the business process model, and provided us with his thesis [63]. Additionally, we thank the dietitians who took part in the expert interviews and Martin Gäbler, who translated the figures into English.

Conflicts of Interest: The authors declare no conflict of interest. G.G. is an employee of the Austrian Association of Dietitians and is interested in the article being published.

\section{References}

1. Porter, M.E.; Larsson, S.; Lee, T.H. Standardizing Patient Outcomes Measurement. N. Engl. J. Med. 2016, 374, 504-506. [CrossRef] [PubMed]

2. Vanherle, K.; Werkman, A.; Baete, E.; Barkmeijer, A.; Kolm, A.; Gast, C.; Ramminger, S.; Höld, E.; Kohlenberg-Müller, K.; Ohlrich-Hahn, S.; et al. Proposed standard model and consistent terminology for monitoring and outcome evaluation in different dietetic care settings: Results from the EU-sponsored IMPECD project. Clin. Nutr. 2018, 37, 2206-2216. [CrossRef] [PubMed]

3. Swan, W.; Vivanti, A.; Hakel-Smith, N.A.; Hotson, B.; Orrevall, Y.; Trostler, N.; Howarter, K.B.; Papoutsakis, C. Nutrition Care Process and Model Update: Toward Realizing People-Centered Care and Outcomes Management. J. Acad. Nutr. Diet. 2017, 117, 2003-2014. [CrossRef] [PubMed] 
4. Vreeman, D.J.; Richoz, C. Possibilities and Implications of Using the ICF and Other Vocabulary Standards in Electronic Health Records. Physiother. Res. Int. 2013, 20, 210-219. [CrossRef]

5. World Health Organization. Internationale Klassifikation der Funktionsfähigkeit, Behinderung und Gesundheit (ICF); Deutschen Institut für Medizinische Dokumentation und Information (DIMDI); World Health Organization: Genf, Switzerland, 2005.

6. World Health Organization. International Classification of Functioning, Disability and Health: ICF; World Health Organization: Geneva, Switzerland, 2001.

7. Escorpizo, R.; Kostanjsek, N.; Kennedy, C.; Nicol, M.M.R.; Stucki, G.; Üstün, T.B. Harmonizing WHO's International Classification of Diseases (ICD) and International Classification of Functioning, Disability and Health (ICF): Importance and methods to link disease and functioning. BMC Public Health 2013, 13, 742. [CrossRef]

8. Madden, R.; Marshall, R.; Race, S. ICF and casemix models for healthcare funding: Use of the WHO family of classifications to improve casemix. Disabil. Rehabil. 2012, 35, 1074-1077. [CrossRef]

9. Donada, M.; Della Mea, V.; Cumerlato, M.; Rankin, N.; Madden, R. A System for Supporting Development and Update of the International Classification of Health Interventions (ICHI). Stud. Health Technol. Inform. 2018, 247, 895-899. [CrossRef]

10. Madden, R.; Sykes, C.; Ustun, T. World Health Organization Family of International Classifications: Definition, Scope and Purpose; World Health Organization: Geneva, Switzerland, 2007.

11. Stucki, G.; Bickenbach, J. Functioning information in the learning health system. Eur. J. Phys. Rehabil. Med. 2017, 53, 139-143. [CrossRef]

12. Stucki, G.; Bickenbach, J. Functioning: The third health indicator in the health system and the key indicator for rehabilitation. Eur. J. Phys Rehabil. Med. 2017, 53, 134-138. [CrossRef]

13. Rauch, A.; Cieza, A.; Stucki, G. How to apply the International Classification of Functioning, Disability and Health (ICF) for rehabilitation management in clinical practice. Eur. J. Phys. Rehabil. Med. 2008, 44, 329-342.

14. Kotsougiani-Fischer, D.; Choi, J.S.; Oh-Fischer, J.S.; Diehm, Y.F.; Haug, V.F.; Harhaus, L.; Gazyakan, E.; Hirche, C.; Kneser, U.; Fischer, S. ICF-based multidisciplinary rehabilitation program for complex regional pain syndrome of the hand: Efficacy, long-term outcomes, and impact of therapy duration. BMC Surg. 2020, 20, 306. [CrossRef]

15. Zhang, M.; Zhang, Y.; Xiang, Y.; Lin, Z.; Shen, W.; Wang, Y.; Wang, L.; Yu, J.; Yan, T. A team approach to applying the International Classification of Functioning, Disability and Health Rehabilitation set in clinical evaluation. J. Rehabil. Med. 2021, 53, jrm00147. [CrossRef] [PubMed]

16. Stucki, G.; Pollock, A.; Engkasan, J.P.; Selb, M. How to use the International Classification of Functioning, Disability and Health as a reference system for comparative evaluation and standardized reporting of rehabilitation interventions. Eur. J. Phys. Rehabil. Med. 2019, 55, 384-394. [CrossRef] [PubMed]

17. Brunani, A.; Raggi, A.; Sirtori, A.; Berselli, M.E.; Villa, V.; Ceriani, F.; Corti, S.; Leonardi, M.; Capodaglio, P.; ICF-OBESITY Group An ICF-Based Model for Implementing and Standardizing Multidisciplinary Obesity Rehabilitation Programs within the Healthcare System. Int. J. Environ. Res. Public Health 2015, 12, 6084-6091. [CrossRef] [PubMed]

18. Brunani, A.; Sirtori, A.; Capodaglio, P.; Donini, L.M.; Buscemi, S.; Carbonelli, M.G.; Giordano, F.; Mazzali, G.; Pasqualinotto, L.; Zenti, M.G.; et al. Disability assessment in an Italian cohort of patients with obesity using an International Classification of Functioning, Disability and Health (ICF)-derived questionnaire. Eur. J. Phys. Rehabil. Med. 2021, 57, 630-638. [CrossRef]

19. Selb, M.; Escorpizo, R.; Kostanjsek, N.; Stucki, G.; Üstün, B.; Cieza, A. A guide on how to develop an International Classification of Functioning, Disability and Health Core Set. Eur. J. Phys. Rehabil. Med. 2015, 51, 105-117.

20. Zangger, M.; Weber, C.; Stute, P. Developing an ICF Core Set for Climacteric Syndrome based on the International Classification of Functioning, Disability and Health (ICF). Maturitas 2020, 143, 197-202. [CrossRef] [PubMed]

21. Tomandl, J.; Book, S.; Hoefle, A.; Graessel, E.; Sieber, C.; Freiberger, E.; Kuehlein, T.; Hueber, S.; Gotthardt, S. Laying the foundation for a primary care core set of the International Classification of Functioning, Disability and Health (ICF) for community-dwelling older adults: A qualitative study. J. Rehabil. Med. 2021, 53, jrm00150. [CrossRef]

22. Stucki, A.; Cieza, A.; Michel, F.; Stucki, G.; Bentley, A.; Culebras, A.; Tufik, S.; Kotchabhakdi, N.; Tachibana, N.; Ustun, B.; et al Developing ICF Core Sets for persons with sleep disorders based on the International Classification of Functioning, Disability and Health. Sleep Med. 2008, 9, 191-198. [CrossRef]

23. Stucki, A.; Daansen, P.; Fuessl, M.; Cieza, A.; Huber, E.; Atkinson, R.L.; Kostanjsek, N.; Stucki, G.; Ruof, J. ICF Core Sets for obesity. J. Rehabil. Med. 2004, 36, 107-113. [CrossRef]

24. Stucki, G.; Cieza, A.; Geyh, S.; Battistella, L.R.; Lloyd, J.; Symmons, D.; Kostanjsek, N.; Schouten, J.; Schouten, J.S. ICF Core Sets for rheumatoid arthritis. J. Rehabil. Med. 2004, 36, 87-93. [CrossRef] [PubMed]

25. Tschiesner, U.; Linseisen, E.; Becker, S.; Mast, G.; Rogers, S.N.; Walvekar, R.R.; Berghaus, A.; Cieza, A. Content validation of the international classification of functioning, disability and health core sets for head and neck cancer: A multicentre study. J. Otolaryngol.-Head Neck Surg. 2010, 39, 674-687. [PubMed]

26. Viehoff, P.B.; Potijk, F.; Damstra, R.J.; Heerkens, Y.F.; Van Ravensberg, C.D.; Van Berkel, D.M.; Neumann, H.A.M. Identification of relevant ICF (International Classification of Functioning, Disability and Health) categories in lymphedema patients: A cross-sectional study. Acta Oncol. 2015, 54, 1-7. [CrossRef] [PubMed]

27. Xie, F.; Lo, N.; Lee, H.; Cieza, A.; Li, S. Validation of the International Classification of Functioning, Disability, and Health (ICF) Brief Core Set for osteoarthritis. Scand. J. Rheumatol. 2008, 37, 450-461. [CrossRef] [PubMed] 
28. Coenen, M.; Kus, S.; Rudolf, K.-D.; Müller, G.; Berno, S.; Dereskewitz, C.; MacDermid, J. Do patient-reported outcome measures capture functioning aspects and environmental factors important to individuals with injuries or disorders of the hand? J. Hand Ther. 2013, 26, 332-342. [CrossRef]

29. D'Amico, D.; Tepper, S.J.; Guastafierro, E.; Toppo, C.; Leonardi, M.; Grazzi, L.; Martelletti, P.; Raggi, A. Mapping Assessments Instruments for Headache Disorders against the ICF Biopsychosocial Model of Health and Disability. Int. J. Environ. Res. Public Health 2020, 18, 246. [CrossRef] [PubMed]

30. Alghwiri, A.A.; Almhdawi, K.A.; Marchetti, G. Are fatigue scales the same? A content comparison using the International Classification of Functioning, Disability and Health. Mult. Scler. Relat. Disord. 2020, 46, 102596. [CrossRef] [PubMed]

31. Cieza, A.; Stucki, G. Content comparison of health-related quality of life (HRQOL) instruments based on the international classification of functioning, disability and health (ICF). Qual. Life Res. 2005, 14, 1225-1237. [CrossRef]

32. Prodinger, B.; Cieza, A.; Williams, D.A.; Mease, P.; Boonen, A.; Kerschan-Schindl, K.; Fialka-Moser, V.; Smolen, J.; Stucki, G.; Machold, K.; et al. Measuring health in patients with fibromyalgia: Content comparison of questionnaires based on the International Classification of Functioning, Disability and Health. Arthritis Care Res. 2008, 59, 650-658. [CrossRef]

33. Stamm, T.A.; Cieza, A.; Machold, K.P.; Smolen, J.S.; Stucki, G. Content comparison of occupation-based instruments in adult rheumatology and musculoskeletal rehabilitation based on the International Classification of Functioning, Disability and Health Arthritis Care Res. 2004, 51, 917-924. [CrossRef]

34. Stucki, A.; Borchers, M.; Stucki, G.; Cieza, A.; Amann, E.; Ruof, J. Content comparison of health status measures for obesity based on the international classification of functioning, disability and health. Int. J. Obes. 2006, 30, 1791-1799. [CrossRef]

35. Patel, K.; Straudi, S.; Ng, Y.S.; Fayed, N.; Melvin, J.L.; Sivan, M. Applying the WHO ICF Framework to the Outcome Measures Used in the Evaluation of Long-Term Clinical Outcomes in Coronavirus Outbreaks. Int. J. Environ. Res. Public Health 2020, 17, 6476. [CrossRef]

36. Cairns, I.; Lindsay, K.; Dalbeth, N.; Díaz-Torné, C.; Pou, M.A.; Diez, B.R.; Pujol-Ribera, E.; Panter, C.; Arbuckle, R.; Tatlock, S.; et al. The impact of gout as described by patients, using the lens of The International Classification of Functioning, Disability and Health (ICF): A qualitative study. BMC Rheumatol. 2020, 4, 1-9. [CrossRef] [PubMed]

37. Coenen, M.; Cabello, M.; Umlauf, S.; Ayuso-Mateos, J.L.; Anczewska, M.; Tourunen, J.; Leonardi, M.; Cieza, A.; PARADISE Consortium. Psychosocial difficulties from the perspective of persons with neuropsychiatric disorders. Disabil. Rehabil. 2015, 38, 1134-1145. [CrossRef] [PubMed]

38. Stamm, T.A.; Machold, K.; Sahinbegovic, E.; Haider, S.; Ernst, M.; Binder, A.; Dallos, T.; Zwerina, J.; Smolen, J. Daily functioning and health status in patients with hand osteoarthritis: Fewer differences between women and men than expected. Wien. Klin. Wochenschr. 2011, 123, 603-606. [CrossRef]

39. Van Leeuwen, L.M.; Pronk, M.; Merkus, P.; Goverts, S.T.; Anema, J.R.; Kramer, S.E. Developing an intervention to implement an ICF-based e-intake tool in clinical otology and audiology practice. Int. J. Audiol. 2019, 59, 282-300. [CrossRef]

40. Van Leeuwen, L.M.; Pronk, M.; Merkus, P.; Goverts, S.T.; Terwee, C.B.; Kramer, S.E. Operationalization of the Brief ICF Core Set for Hearing Loss: An ICF-Based e-Intake Tool in Clinical Otology and Audiology Practice. Ear Hear. 2020, 41, 1533-1544. [CrossRef] [PubMed]

41. Appleby, H.; Tempest, S. Using Change Management Theory to Implement the International Classification of Functioning, Disability and Health (ICF) in Clinical Practice. Br. J. Occup. Ther. 2006, 69, 477-480. [CrossRef]

42. Tempest, S.; Harries, P.; Kilbride, C.; De Souza, L. Enhanced clarity and holism: The outcome of implementing the ICF with an acute stroke multidisciplinary team in England. Disabil. Rehabil. 2013, 35, 1921-1925. [CrossRef]

43. Tempest, S.; Harries, P.; Kilbride, C.; De Souza, L. To adopt is to adapt: The process of implementing the ICF with an acute stroke multidisciplinary team in England. Disabil. Rehabil. 2012, 34, 1686-1694. [CrossRef]

44. Tempest, S.; Jefferson, R. Engaging with clinicians to implement and evaluate the ICF in neurorehabilitation practice. NeuroRehabilitation 2015, 36, 11-15. [CrossRef] [PubMed]

45. Mukaino, M.; Prodinger, B.; Yamada, S.; Senju, Y.; Izumi, S.-I.; Sonoda, S.; Selb, M.; Saitoh, E.; Stucki, G. Supporting the clinical use of the ICF in Japan-development of the Japanese version of the simple, intuitive descriptions for the ICF Generic-30 set, its operationalization through a rating reference guide, and interrater reliability study. BMC Health Serv. Res. 2020, 20, 1-16. [CrossRef] [PubMed]

46. Coenen, M.; Rudolf, K.-D.; Kus, S.; Dereskewitz, C. The International Classification of Functioning, Disability and Health (ICF): The implementation of the ICF Core Sets for Hand Conditions in clinical routine as an example of application. Bundesgesundheitsblatt-Gesundh.-Gesundh. 2018, 61, 787-795. [CrossRef]

47. Maritz, R.; Aronsky, D.; Prodinger, B. The International Classification of Functioning, Disability and Health (ICF) in Electronic Health Records. Appl. Clin. Inform. 2017, 8, 964-980. [CrossRef] [PubMed]

48. Cozzi, S.; Martinuzzi, A.; Della Mea, V. Ontological modeling of the International Classification of Functioning, Disabilities and Health (ICF): Activities \& Participation and Environmental Factors components. BMC Med. Inform. Decis. Mak. 2021, $21,1-21$. [CrossRef]

49. RIS. Bundesgesetz über die Regelung der gehobenen medizinisch-technischen Dienste (MTD-Gesetz) StF: BGBl. Nr. 460/1992. Available online: https://www.ris.bka.gv.at/GeltendeFassung.wxe?Abfrage=Bundesnormen\&Gesetzesnummer=10010701 (accessed on 10 February 2022). 
50. Gäbler, G.; Coenen, M.; Lycett, D.; Stamm, T. Towards a standardized nutrition and dietetics terminology for clinical practice: An Austrian multicenter clinical documentation analysis based on the International Classification of Functioning, Disability and Health (ICF)-Dietetics. Clin. Nutr. 2019, 38, 791-799. [CrossRef] [PubMed]

51. Gäbler, G.J.; Coenen, M.; Bolleurs, C.; Visser, W.K.; Runia, S.; Heerkens, Y.F.; Stamm, T.A. Toward Harmonization of the Nutrition Care Process Terminology and the International Classification of Functioning, Disability and Health-Dietetics: Results of a Mapping Exercise and Implications for Nutrition and Dietetics Practice and Research. J. Acad. Nutr. Diet. 2018, 118, 13-20.e13. [CrossRef] [PubMed]

52. Gäbler, G. Towards Harmonization of Nutrition and Dietetics Terminologies for Clinical Practice and Research. Development of the Austrian ICF-Dietetics. Available online: https:/ / resolver.obvsg.at/urn:nbn:at:at-ubmuw:1-21174 (accessed on 10 September 2020).

53. ICF Case Studies: Introduction to ICF-based Documentation Tools and Rehab-Cyclea. Available online: https://www.icfcasestudies.org/introduction/introduction-to-icf-based-documentation-tools-and-rehab-cycle-2/ (accessed on 6 July 2021).

54. Gäbler, G.; Coenen, M.; Fohringer, K.; Trauner, M.; Stamm, T. Towards a nationwide implementation of a standardized nutrition and dietetics terminology in clinical practice: A pre-implementation focus group study including a pretest and using the Consolidated Framework for Implementation Research. BMC Health Serv. Res. 2019, 19, 1-19. [CrossRef]

55. Ehlers, F.; Eichstädter, R.; Haux, R.; Pohl, U.; Resch, F.; Ammenwerth, E. Systems analysis in health care: Framework and example. Methods Inf. Med. 2002, 41, 134-140. [CrossRef]

56. Kuo, K.-M.; Liu, C.-F.; Talley, P.C.; Pan, S.-Y. Strategic Improvement for Quality and Satisfaction of Hospital Information Systems. J. Health Eng. 2018, 2018, 1-14. [CrossRef]

57. ISO/IEC TS 33061; 2021 Information Technology—Process Assessment-Process Assessment Model for Software Life Cycle Processes. ISO: London, UK, 2021.

58. Ammenwerth, E.; Haux, R. IT-Projektmanagement in Krankenhaus und Gesundheitswesen; Schattauer: Stuttgart, Germany, 2005.

59. Waterman, H.; Tillen, D.; Dickson, R.; De Koning, K. Action research: A systematic review and guidance for assessment. Health Technol. Assess. 2001, 5, iii-157.

60. Laur, C.; Keller, H. Implementing best practice in hospital multidisciplinary nutritional care: An example of using the knowledgeto-action process for a research program. J. Multidiscip. Health 2015, ume 8, 463-472. [CrossRef]

61. Montgomery, A.; Doulougeri, K.; Panagopoulou, E. Implementing action research in hospital settings: A systematic review. J. Health Organ. Manag. 2015, 29, 729-749. [CrossRef] [PubMed]

62. Gäbler, G.; Hofbauer, A. (Eds.) Der Diaetologische Prozess. Qualitätsstandard für die diaetologische Praxis, 1st ed.; Verband der Diaetologen Österreichs: Wien, Austria, 2020; p. 145.

63. Krottenmüller, P. Analyse der Integration Diätologischer Prozesse in ein Krankenhausinformationssystem. Analysis of the Integration of Nutriton Care Processes in Hospital Information Systems). Available online: https:/ / repositorium.meduniwien.ac. at/obvumwhs/content/titleinfo/5121213?query=krotte (accessed on 10 September 2020).

64. Bundesministerium des Innern, für Bau und Heimat/Bundesverwaltungsamt. Organisationshandbuch. 6.2.4 Prozessmodelle. Available online: https://www.orghandbuch.de/OHB/DE/Organisationshandbuch/6_MethodenTechniken/62 _Dokumentationstechniken/624_Prozessmodelle/prozessmodelle-node.html (accessed on 5 May 2020).

65. Scheer, A.-W. ARIS-Modellierungsmethoden, Metamodelle, Anwendungen; Springer: Berlin/Heidelberg, Germany, 2006.

66. Edrawsoft. Eine Leistungsstarke All-in-One-Diagrammsoftware. Available online: https://www.edrawsoft.com/de/ (accessed on 6 June 2020).

67. SAP AG (Systems Applications Programs AG). SAP ERP INDUSTRY EXTENSION HEALTHCARE 6.0; SAP Österreich GmbH: Wien, Austria, 2011.

68. SAP AG (Systems Applications Programs AG). IS-H Branchenkomponente Krankenhaus Release-Informationen; SAP Österreich GmbH: Wien, Austria, 2006.

69. Cerner Deutschland. i.s.h.med. Das Universelle, in Die SAP-Welt Integrierte KIS. Available online: https://www.cerner.com/de/ de/loesungen/ishmed (accessed on 17 January 2020).

70. Hakel-Smith, N.; Lewis, N.M.; Eskridge, K.M. Orientation to Nutrition Care Process Standards Improves Nutrition Care Documentation by Nutrition Practitioners. J. Am. Diet. Assoc. 2005, 105, 1582-1589. [CrossRef]

71. ID Information und Dokumentation im Gesundheitswesen. ID DIACOS ${ }^{\circledR}$. Available online: https://www.id-berlin.de/produkte/ codierung/id-diacos/ (accessed on 5 May 2021).

72. Bales, M.E.; Kukafka, R.; Burkhardt, A.; Friedman, C. Qualitative assessment of the International Classification of Functioning, Disability, and Health with respect to the desiderata for controlled medical vocabularies. Int. J. Med. Inform. 2006, 75, 384-395. [CrossRef] [PubMed]

73. World Health Organization. How to use the ICF: A Practical Manual for Using the International Classification of Functioning, Disability, and Health (ICF); WHO: Geneva, Switzerland, 2013.

74. Murphy, S.N.; Weber, G.; Mendis, M.; Gainer, V.; Chueh, H.C.; Churchill, S.; Kohane, I. Serving the enterprise and beyond with informatics for integrating biology and the bedside (i2b2). J. Am. Med. Inform. Assoc. 2010, 17, 124-130. [CrossRef]

75. Sholle, E.T.; Cusick, M.; Davila, M.; Kabariti, J.; Flores, S.; Campion, T.R. Characterizing Basic and Complex Usage of i2b2 at an Academic Medical Center. AMIA Jt. Summits Transl. Sci. proceedings. AMIA Jt. Summits Transl. Sci. 2020, 2020, 589-596. 
76. Hripcsak, G.; Duke, J.D.; Shah, N.H.; Reich, C.G.; Huser, V.; Schuemie, M.J.; Suchard, M.A.; Park, R.W.; Wong, I.C.K.; Rijnbeek, P.R.; et al. Observational Health Data Sciences and Informatics (OHDSI): Opportunities for Observational Researchers. Stud. Health Technol. Inform. 2015, 216, 574-578. [CrossRef]

77. Chan, C.-L.; Chang, C.-C. Big Data, Decision Models, and Public Health. Int. J. Environ. Res. Public Health 2020, $17,6723$. [CrossRef]

78. eHealth Network of European Commission. Guidelines on Minimum/Non-Exhaustive Patient Summary Dataset for Electronic Exchange. In Accordance with the Cross-Border Directive 2011/24/EU; eHealth Network of European Commission: Brussels, Belgium, 2013.

79. European Commission. Innovative healthcare for the 21st century. Communication from the commission to the European parliament, the council, the European economic and social committee and the committee of the regions. In eHealth Action Plan 2012-2020; European Commission: Brussels, Belgium, 2012.

80. Schuntermann, M.F. The implementation of the International Classification of Functioning, Disability and Health in Germany: Experiences and problems. Int. J. Rehabil. Res. 2005, 28, 93-102. [CrossRef] [PubMed]

81. Grill, E.; Gloor-Juzi, T.; Huber, E.; Stucki, G. Assessment of functioning in the acute hospital: Operationalisation and reliability testing of ICF categories relevant for physical therapists interventions. J. Rehabil. Med. 2011, 43, 162-173. [CrossRef] [PubMed]

82. Uhlig, T.; Lillemo, S.; Moe, R.H.; Stamm, T.; Cieza, A.; Boonen, A.; Mowinckel, P.; Kvien, T.K.; Stucki, G. Reliability of the ICF Core Set for rheumatoid arthritis. Ann. Rheum. Dis. 2007, 66, 1078-1084. [CrossRef] [PubMed]

83. Uhlig, T.; Moe, R.; Reinsberg, S.; Kvien, T.K.; Cieza, A.; Stucki, G. Responsiveness of the International Classification of Functioning, Disability and Health (ICF) Core Set for rheumatoid arthritis. Ann. Rheum. Dis. 2009, 68, 879-884. [CrossRef]

84. Escorpizo, R.; Stucki, G.; Cieza, A.; Davis, K.; Stumbo, T.; Riddle, D.L. Creating an Interface Between the International Classification of Functioning, Disability and Health and Physical Therapist Practice. Phys. Ther. 2010, 90, 1053-1063. [CrossRef]

85. Ash, J.; Berg, M.; Coiera, E. Viewpoint Paper: Some Unintended Consequences of Information Technology in Health Care: The Nature of Patient Care Information System-related Errors. J. Am. Med. Inform. Assoc. JAMIA 2004, 11, 104-112. [CrossRef]

86. RIS. Verordnung der Bundesministerin Für Gesundheit und Frauen über Fachhochschul-Bakkalaureatsstudiengänge für die Ausbildung in den Gehobenen Medizinisch-Technischen Diensten (FH-MTD-Ausbildungsverordnung-FH-MTD-AV) StF: BGB1. II Nr. 2/2006. Available online: https:/ / www.ris.bka.gv.at/GeltendeFassung.wxe?Abfrage=Bundesnormen\&Gesetzesnummer= 20004516 (accessed on 10 February 2022).

87. Lacey, K.; Pritchett, E. Nutrition Care Process and Model: ADA adopts road map to quality care and outcomes management. J. Am. Diet. Assoc. 2003, 103, 1061-1072. [CrossRef]

88. Hakel-Smith, N.; Lewis, N.M. A standardized nutrition care process and language are essential components of a conceptual model to guide and document nutrition care and patient outcomes. J. Am. Diet. Assoc. 2004, 104, 1878-1884. [CrossRef]

89. Writing Group of the Nutrition Care Process/Standardized Language Committee Nutrition Care Process Part II: Using the International Dietetics and Nutrition Terminology to Document the Nutrition Care Process. J. Am. Diet. Assoc. 2008, 108, 1287-1293. [CrossRef] [PubMed] 